\title{
7 \\ Cytomorphological Profile and Patterns of Lymphadenopathy
}

\section{IJCRR}

Section: Healthcare

Sci. Journal Impact

Factor: 6.1 (2018)

ICV: 90.90 (2018)

(c) (7) (8)

Copyright@IJCRR

\section{Anil Meena ${ }^{1}$, Gajendra Pal Singh Uike ${ }^{2}$, Jagannath Jatav ${ }^{3}$}

'Associate Professor, Department of Pathology, Government Medical College Ratlam (MP) 4570o1, India; ${ }^{2}$ Assistant Professor, Department of Pathology, Gajra Raja Medical College, Gwalior (MP) 474002, India; ${ }^{3}$ Assistant Professor, Department of Pathology, Shyam Shah Medical College, Rewa (MP) 486001, India.

\section{ABSTRACT}

Background: Enlargement of lymph nodes or lymphadenopathy is one of the ubiquitous clinical presentations of patients attending the outpatient department (OPD). Fine-needle aspiration cytology (FNAC), as the initial investigation, has assumed importance in diagnosing various diseases. It is a cost-effective, reliable, immediate, preliminary, relatively little traumatic procedure compared to open biopsy. However, there is not always a specific diagnosis, thus providing ample information for further management and reducing the amount of open biopsy.

Objectives: In the present study, we identified the pattern of diseases in the different anatomical locations of lymph nodes and the role of FNAC in the diagnosis of diseases.

Materials and Methods: A two-year study of 920 cases of lymphadenopathy presenting to the Department from January 2016 to December 2017 taken up for our study. FNAC performed using a 23/24 gauge needle and a 20 ml syringe. Four of the prepared smears, two were fixed in alcohol and stained with hematoxylin and eosin and Papanicolaou stain. Two smears air-dried, one stained with Leishman stain, and the other by May-Grunwald-Giemsa (MGG) stain. Special stains like periodic acid-Schiff for mucin (PAS) and Ziehl-Neelsen stain (ZN) stain for acid-fast bacilli (AFB) performed for the diagnosis of peculiar lesions.

Results: Most common lesion observed in our study was reactive lymphadenitis (33.26\%), followed by granulomatous lymphadenitis (28.15\%), tubercular lymphadenitis (17.39\%) and metastatic lesions (14.23\%). Cervical lymphadenopathy found to be the most common site in our study.

Conclusion: Our study highlighted the various morphological patterns and incidence of lymphadenopathy concerning various regions and sex. FNAC as a straightforward, cost-effective, relatively painless, quick, repeatable, and reliable method of investigation for lymphadenopathy and also very useful in developing countries like India where costly investigations are not easily affordable.

Key Words: Fine Needle Aspiration Cytology (FNAC), Granulomatous Lymphadenitis, May-Grunwald-Giemsa (MGG) stain, Metastatic Lesions

\section{INTRODUCTION}

Enlargement of a lymph node is known as lymphadenopathy, is one of the excellent clinical presentations of patients in the outdoor department of a hospital. Lymph nodes incorporate an essential part of the defence system of the human body. They are kidney-shaped, small, rounded, nodules of lymphoid tissue that perform nonspecific filtration of particulate matter and micro-organisms from lymph. Fine needle aspiration cytology (FNAC) of lymph node aspiration is of great value for diagnosing lymphadenitis or infectious disease, lymphomas, and metastatic carcinoma. Lymphadenopathy is a clinical presentation of the regional or systemic disease that serves as an outstanding clue to the underlying condition. ${ }^{1,2}$ It can arise from infectious, benign, and malignant causes depending on the geographical circumstances and socioeconomic status. ${ }^{1}$ FNAC is a trouble-free, safe, quick, reliable, and cost-effective method of establishing the lesions' diagnosis and also helps in indicating the pattern of the investigation. ${ }^{2}$ Knowing the pattern of lymphadenopathy in a given geographical region is essential for making a confident diagnosis or suspecting a disease. In a developing country like India, Bangladesh and Pakistan the major cause of lymphadenopathy are tubercular infections. ${ }^{3}$ Cytology of

\section{Corresponding Author:}

Dr. Anil Meena, Associate Professor, Department of pathology, Government Medical College, Ratlam (M.P.) 457001, India; Mob: 09893604205; Email: meenaanil10@gmail.com

ISSN: 2231-2196 (Print)

Received: 18.08 .2020
ISSN: $0975-5241$ (Online)

Revised: 29.09 .2020
Accepted: 19.10 .2020
Published: 14.12 .2020 
lymph nodes has become an indication for the diagnosis of many diseases due to before the usual time availability of results, simplicity, and minimal traumatic with less complication. FNAC has also been advocated as a beneficial method compared to excision biopsies, especially in developing countries with limited financial and healthcare resources like India. When combined, adequate material and potentially viable make the fine-needle aspiration cytology of equal significance as a histological examination. In many clinical settings, it is challenging to decide which patient is more likely to have reactive or neoplastic lymphadenopathy. Here, knowledge about the pattern of lymphadenopathy helps the clinician solve the diagnostic dilemma. ${ }^{4}$

\section{MATERIALS AND METHODS}

The fine-needle cytological examination of 920 cases of lymphadenopathy presenting to the Department of Pathology, Jayarogya Hospital, and Gajra Raja Medical College Gwalior (M.P) India, for two years from January 2016 to December 2017, was taken up for our retrospective study. Entire data is based on medical record data, thereby ethical clearance is not mandatory. All lymphadenopathy cases referred by the clinicians from the outpatient department (OPD) of different departments of our institute, including Medicine, Surgery, Pediatric, Orthopedic, and Gynaecology. A brief clinical history and physical examination and evaluation of relevant investigations carried out of each patient; the FNAC procedure performed under strict aseptic conditions. We used a 23/24 gauge needle and a 20-mL plastic syringe with a detachable syringe holder (Franzen's aspiration handle). Multiple sites were aspirated. The aspirated material smeared onto four slides in each case. Out of four slides, two slides immediately immersed in 95\% ethanol, and the remaining two slides air-dried. The alcohol fixed smears stained by hematoxylin and eosin stain and Papanicolaou stain and the air-dried smears routinely stained by MayGrunwald-Giemsa (MGG) stain and Leishman stain. Special stains like periodic acid-Schiff for mucin (PAS) and ZiehlNeelsen stain (Z.N.) stain for acid-fast bacilli (AFB) done whenever required. The diagnosis was categorized according to various morphological patterns and correlated clinically. In 206 cases $(21.45 \%)$, histology and cytology correlation was available. In our study, we followed Standard guidelines for cytological diagnosis as far as practicable. At the end of the study, data analyzed using computer software (Microsoft Excel for Windows and Epi Info version 6.2).

\section{RESULTS}

Over two years from January 2016 to December 2017, a total of 920 cases of lymphadenopathy subjected to FNAC, of which 905 cases (\%) yielded adequate material for interpretation, and 15 cases produced (\%) inadequate material. Of these, 206 cases $(21.45 \%)$ followed by histopathological examination. The age ranged of patients presenting with lymphadenopathy was from 6 months to 81 years, and the mean age was 22.34 years. In our study, a male-to-female ratio of 1.8:1 was observed, with males were denoting 498 cases $(54.13 \%)$, and females were contributing 422 facts $(45.86 \%)$ [Table 1]. Out of 920 patients, superficial lymphadenopathy was in $890(96.73 \%)$ patients, and deep-seated lymphadenopathy was $30(3.26 \%)$ patients. Fine needle aspiration performed in deep-seated enlarged lymph nodes under image guidance of computed tomography and ultrasonography.

The cervical region found to be the most common site of lymphadenopathy 539 cases $(58.69 \%)$ followed by axillary region 153 cases (16.63\%), inguinal region 138 cases (15.00\%), abdominal area 44 cases $(4.78 \%)$ and mediastinal region 22 cases $(2.39 \%)$ [ Table 1$)$.

\begin{tabular}{|c|c|c|c|c|}
\hline S.N. & $\begin{array}{c}\text { Lymph } \\
\text { node region }\end{array}$ & $\begin{array}{l}\text { Male, } \\
\text { n (\%) }\end{array}$ & $\begin{array}{c}\text { Female, } \\
\text { n (\%) }\end{array}$ & $\begin{array}{l}\text { Total, } \\
\text { n (\%) }\end{array}$ \\
\hline 1 & Cervical & $278(55.82 \%)$ & $261(61.84 \%)$ & $539(58.69 \%)$ \\
\hline 2 & Axillary & $81(16.27 \%)$ & $72(17.06 \%)$ & $153(16.63 \%)$ \\
\hline 3 & Inguinal & $79(15.86 \%)$ & $59(13.98 \%)$ & $138(15.00 \%)$ \\
\hline 4 & Abdominal & $28(05.62 \%)$ & 16(03.79\%) & $44(04.78 \%)$ \\
\hline 5 & Mediastinal & $14(02.81 \%)$ & $8(01.89 \%)$ & $22(02.39 \%)$ \\
\hline 6 & Generalized & $18(03.61 \%)$ & $6(01.42 \%)$ & $24(02.60 \%)$ \\
\hline 7 & Total & $498(100 \%)$ & $422(100 \%)$ & $920(100 \%)$ \\
\hline
\end{tabular}

In males, the maximum cases of lymphadenopathy found to be reactive lymphadenitis 160 cases $(31.93 \%)$ followed by granulomatous lymphadenitis 142 cases $(28.34 \%)$, metastatic lesions 78 cases $(15.56 \%)$, tubercular lymphadenitis 62 cases $(12.37 \%)$, suppurative granulomatous lymphadenitis 25 cases (4.99\%), acute suppurative lymphadenitis 12 cases $(2.39 \%)$, non-Hodgkins lymphoma 9 cases $(1.79 \%)$ and Hodgkins lymphoma 4 cases $(0.79 \%)$ [Table 2]. While, in females the most common cause was reactive hyperplasia 119 cases $(28.40 \%)$ followed granulomatous lymphadenitis 96 cases $(22.91 \%)$, tubercular lymphadenitis 93 cases (22.19\%), metastatic lesions 53 cases (12.64\%), Suppurative granulomatous lymphadenitis 21 cases (5.01\%), acute suppurative lymphadenitis 18 cases $(4.29 \%)$, non-Hodgkins lymphoma 10 cases $(2.38 \%)$, and Hodgkins lymphoma 4 cases $(0.79 \%)$ [Table 2]. 
Table 2: Cytological diagnosis of 920 cases of lymphadenopathy

\begin{tabular}{llccc} 
S.N. & Cytological diagnosis & Male, $\mathbf{n}(\%)$ & Female, $\mathbf{n}(\%)$ & n (\%) \\
1 & Reactive hyperplasia & $160(31.93 \%)$ & $119(28.40 \%)$ & $279(30.32 \%)$ \\
2 & Granulomatous lymphadenitis & $142(28.34 \%)$ & $96(22.91 \%)$ & $238(25.86 \%)$ \\
3 & Tubercular lymphadenitis & $62(12.37 \%)$ & $93(22.19 \%)$ & $155(16.84 \%)$ \\
4 & Metastatic carcinoma & $78(15.56 \%)$ & $53(12.64 \%)$ & $131(14.23 \%)$ \\
5 & Suppurative granulomatous lym- & $25(4.99 \%)$ & $21(5.01 \%)$ & $46(5 \%)$ \\
& phadenitis & & & $30(3.26 \%)$ \\
6 & Acute suppurative lymphadenitis & $12(2.39 \%)$ & $18(4.29 \%)$ & $19(2.06 \%)$ \\
7 & Nonhodgkins lymphoma (NHL) & $9(1.79 \%)$ & $10(2.38 \%)$ & $6(0.65 \%)$ \\
8 & Hodgkins lymphoma (HL) & $4(0.79 \%)$ & $2(0.47 \%)$ & $16(1.73 \%)$ \\
9 & Unsatisfactory & $9(1.79 \%)$ & $7(1.67 \%)$ & $920(100 \%)$ \\
10 & Total & $501(100 \%)$ & $419(100 \%)$ & \\
\hline
\end{tabular}

\section{DISCUSSION}

Lymphadenopathy is a clinical manifestation of the regional or systemic disease serves as an excellent clue to the diagnosis of illness through fine needle aspiration cytological examination. Lymph node lesions showed in patients ranging from very early to advanced age. In the present study, the youngest patient with lymphadenopathy was a six-month male infant, and the oldest one was 81-years-old, with a mean age of 22.34 years. In our study, a male preponderance noted with a male-to-female ratio of $1.8: 1$, which correlated with others. ${ }^{5,6}$ Whereas, some other studies found a slight female preponderance with a male to female ratio of $1: 1.2 .^{7,8}$ The cervical region was the most frequent site of lymphadenopathy in our study $(58.69 \%)$ followed by axillary lymphadenopathy (16.63\%), and inguinal lymphadenopathy $(15.00 \%)$. The cervical region observed the most common site of involvement in other studies. ${ }^{7,9,10}$

Collectively, benign disorders were more common than malignant diseases in the present study and correlated with other studies conducted in India and other developing countries. ${ }^{11,12}$ Reactive lymphadenopathy (30.32\%) was the most common cause of in our study, followed by Granulomatous lymphadenitis (25.86\%) and tubercular lymphadenitis (16.84\%). Similar findings observed in a study conducted by Mainali et al. ${ }^{13}$. In the present study, tubercular lymphadenitis is $3 \mathrm{rd}$ most common lymphadenopathy. Whereas, many other studies from India, Pakistan, and Sudan also found tuberculosis as the most common cause of lymphadenopathy. ${ }^{7,8,12}$ In the present study, 131 patients (14.23\%) had metastatic deposits in the lymph nodes. Adenocarcinoma and squamous cell carcinoma were the most frequent metastatic lesions encountered. Similar findings observed in the study conducted by Shrivastava JP et al. and Al-Alwan NA et al. ${ }^{14,15}$ Lymphomas constituted only $2.71 \%$ of lymphadenopathies in our study, of which Hodgkin's lymphoma represented and NHL; this result corroborated by other studies. ${ }^{6,12}$

\section{CONCLUSION}

This study highlights the utility of FNAC as a simple, costeffective, relatively painless, quick, repeatable, and reliable method of investigation for lymphadenopathy, considerably in OPDs, peripheral hospitals, and dispensaries, as a result of this reducing the event of surgery and hence, bed occupancy. Notwithstanding, it is not a substitute for conventional surgical pathology but is complementary to it.

\section{ACKNOWLEDGEMENT}

Authors acknowledge the immense help received from the scholars whose articles are cited and included in references to this manuscript. The authors are also grateful to authors/ editors / publishers of all those articles, journals and books from where the literature for this article has been reviewed and discussed.

\section{Conflict of interest: Nil}

\section{Source of funding: Nil}

\section{REFERENCES}

1. Qadri SK, Hamdani NH, Shah P, Lone MI, Baba KM. Profile of lymphadenopathy in Kashmir valley: A cytological study. Asian Pac J Cancer Prev 2012;13:3621-5.

2. Wilkinson AR, Mahore SD, Maimoon SA. FNAC in the diagnosis of lymph node malignancies: A simple and sensitive tool. Indian J Med Paediatr Oncol 2012;33:21-4.

3. Bhuyan MA, Fakir MA, Hossain AB, Huq AH, Gupta S. Role of fine-needle aspiration cytology in the diagnosis of cervical lymphadenopathy. Bangladesh J Otorhinolaryngol 2008;14:63-5.

4. Das DK, Gupta SK. Fine needle aspiration cytodiagnosis of Hodgkin's disease and its subtypes. II. Subtyping by differential cell counts. Acta Cytol 1990;34:337-41.

5. Dhingra V, Misra V, Mishra R, Bhatia R, Singhal M. Fine needle aspiration cytology (FNAC) as a diagnostic tool in paediatric lymphadenopathy. J Clin Diagn Res 2010;4:2452-7. 
6. Hirachand S, Lakhey M, Akhter J, Thapa B. Evaluation of fine-needle aspiration cytology of lymph nodes in Kathmandu Medical College, Teaching hospital. Kathmandu Univ Med J 2009; 7:139-42.

7. Nidhi P, Sapna T, Shalini M, Kumud G. FNAC in tuberculous lymphadenitis: Experience from a tertiary level referral centre. Indian J Tuberc 2011;3:102-7.

8. Ageep AK. Assessment of adult peripheral lymphadenopathy in Red Sea State, Sudan. Internet J Trop Dis Health 2011;2:24-32.

9. Pandit AA, Candes FP, Khubchandani SR. Fine needle aspiration cytology of lymph nodes. J Postgrad Med 1987;33:134-6.

10. Ahmed N, Israr S, Ashraf MS. Comparison of fine needleaspiration cytology (FNAC) and excision biopsy in the diagnosis of cervical lymphadenopathy. Pak J Surg 2009;25:72-5.

11. Ahmad SS, Akhtar S, Akhtar K, Naseem S, Mansoor T. Study of fine needle aspiration cytology in lymphadenopathy with special reference to Acid-fast staining in cases of tuberculosis. JK Sci 2005;7:1-4.

12. Fatima S, Arshad S, Ahmed Z, Hasan SH. Spectrum of cytological findings in patients with neck lymphadenopathy - Experience in a tertiary care hospital in Pakistan. Asian Pac J Cancer Prev 2011;12:1873-5.15.

13. Mainali N, Suwal RB. Patterns of lymphadenopathy on fine needle aspiration cytology in eastern Nepal. J Path Nepal 2015; 5:814 -816.

14. Shrivastava JP, Bharat S, Meena A, Jain B. Evaluation of peripheral lymphadenopathy in children in greater Gwalior region. Indian J Appl Res 2015;5:282-4.

15. Al-Alwan NA, Al Hashimi S, Salman NM, Al-Atta EA. Fine needle aspiration cytology versus histopathology in diagnosing lymph node lesions. Acta Cytol 1996;2:320-5. 